\title{
Minute Leaf-litter Thrips of the Genus Preeriella (Thysanoptera, Phlaeothripidae) from Asia
}

\author{
Shûji Okajima \\ Laboratory of Entomology, Tokyo University of Agricullure, \\ Sakuragaoka, Setagaya-ku, Tokyo, 156-8502. Japan
}

(Received 16 July 1997; Accepted 6 July 1998)

\begin{abstract}
The genus Preeriella is redefined and Machadonia is newly synonymized with it. Five species of the genus are recorded from Asia, including four newly described species: $P$. armigera sp. n. from Japan, $P$. bournieri $\mathrm{sp}$. $\mathrm{n}$. from Thailand, $P$. formosana sp. n. from Taiwan, and $P$. malaya sp. n. from West Malaysia. A key to the five Asian species is given. Adults of these species are usually less than $1 \mathrm{~mm}$ long and live in leaf-litter, but it is not known if they are predatory or fungus-feeding. One species, $P$. armigera, has the hind femora of large males greatly enlarged, suggesting some form of sexual competition.

Key Words: Thysanoptera, Phlaeothripidae, hyidiothripine lineage, Preeriella. Machadonia, Asia.
\end{abstract}

\section{Introduction}

The genus Preeriella Hood, 1939 contains exceptionally small, elongate, and laterally compressed species of thrips, and belongs to the hyidiothripine lineage (see Mound and Marullo 1997) of the subfamily Phlaeothripinae. Eleven species of the genus were hitherto known in the world, six from the New World (Mound and Marullo 1996), four from Africa (Hartwig 1978a, 1978b), and one from West Malaysia.

The investigation of the thrips fauna of East Asia, particularly in the tropics and subtropics, is quite insufficient, and prior to this study only one species of Preeriella was known from this region. However, during recent surveys in parts of East Asia made by the present author and his colleagues, large series of specimens determined as Preeriella were obtained, mainly from litter samples. These specimens comprise at least five species, of which four are new to science. No host or habitat specificity was noted, these thrips being found in both wet and dry litter, at both shady and sunny sites, and involving both small and large leaves. In this paper, the genus Preeriella is redefined and the four new species are described and illustrated.

\section{Systematic Relationships}

Superficially, the hyidiothripine lineage is highly specialized and well separated from other members of the family Phlaeothripidae in having the body laterally compressed, the pronotum fused to both the epimeron and episternum due to absence or reduction of the notopleural suture, and by the presence of the spiracle-bearing laterotergite (Fig. 2) separaterd from the tergum on the eighth abdominal segment 
in the female. Because of the prothoracic dorsal plate and the laterotergite, Bhatti (1992) erected the family Hyidiothripidae for this lineage. However, these two character states are also found in the genus Andrethrips Mound, 1974 (Okajima 1998), and are thus not unique to hyidiothripines. Therefore, the family Hyidiothripidae is not employed herein; the term "hyidiothripine lineage" is employed here for the sake of convenience. The classification within the subfamily Phlaeothripinae is still uncertain.

\section{Biological Problems}

Because of their small body size and cryptic habit of living in the leaf-litter, it is very difficult to collect Preeriella species in the field. They can usually be extracted from litter samples by a Tullgren funnel, but little is known of their biology.

Although most leaf-litter phlaeothripine species presumably feed on fungal hyphae, Hartwig (1978a) reported that one South African Preeriella species, $P$. moundi Hartwig, 1978, possibly preys on mites and larvae of other thrips species. However, no particular mites or thrips larvae were collected together with Preeriella species during recent surveys in East Asia.

A species newly described below from Japan and Taiwan, P. armigera, often produces large populations in leaf-litter. The males are somewhat robust and show extreme allometry. Large males have the hind leg enlarged with a tibial subapical tooth and a tarsal hamulus. These structures have also been found in several males collected from Queensland, Australia (L. A. Mound, pers. comm.) and from Thailand. However, this kind of structure has not been reported before in this genus, nor in other phlaeothripine genera. In certain fungus-feeding phlaeothripine species, such enlargement is manifested commonly in fore legs of males, and is associated with competition for females. Crespi (1986a, 1986b, 1988) reported fighting between males in order to secure mating in some colonial fungus-feeding species, such as Elaphrothrips and Hoplothrips species. Those species often make large-sized colonies, and show size-related extreme allometry in males. The males compete with each other, and larger males win fights and secure females more successfully than smaller males. Since its expression is related to body size, the enlarged hind legs of $P$. armigera are presumably associated similarly with sexual competition in some way.

Another problem is the laterally compressed bodies of Preeriella species. Most phlaeothripine species have the bodies more or less depressed dorso-ventrally, and in leaf-litter species often strongly depressed. This laterally compressed body is unusual not only in the Phlaeothripidae but also in other terrestrial Arthropoda. The significance of this body form is still unknown, and requires further study.

Type depository. The holotypes and some of the paratypes designated in this paper are preserved in the Laboratory of Entomology, Tokyo University of Agriculture.

Abbreviations. The following abbreviations are used for the collectors: $\mathrm{HU}-\mathrm{H}$. Urushihara, SO - S. Okajima, TN - T. Nonaka. 


\section{Genus Preeriella Hood}

Preeriella Hood, 1939, 612. Type species: Chirothripoides minutus Watson, 1937 by original designation.

Machadonia Bournier, 1965, 95-96. Type species: Machadonia crassisetis Bournier, 1965 by original designation. Syn. nov.

Small-sized species, usually feeble, thickened dorso-ventrally, wings fully developed or reduced. Head distinctly projected in front of eyes, distinctly longer than broad; a pair of postocular setae well developed, long and stout, usually expanded at apex. Antennae seven- or eight-segmented; segment III reduced, short and broad, broadly joined to segment IV, these two segments well separated from each other, or scarcely divided by a suture, or completely fused; segment IV large; segment VIII long and slender, campaniform sensorium on segment Il situated at the middle. Mouth-cone short and rounded; maxillary stylets retracted into head capsule, rather wide apart, subparallel; maxillary bridge invisible. Pronotum well developed, usually not separated from episternum; usually with a median transverse groove; prominent setae of prothorax usually expanded at apex, anteroangular and anteromarginal setae close together, midlaterals usually reduced. Basantra and ferna present but weak; prospinasternum widely developed, mesopresternum absent. Fore femora without stout spine; fore tarsal tooth absent in both sexes. Metathoracic sternopleural suture absent. Wings, if fully developed, weak, without duplicated cilia. Abdominal tergum I divided into several sclerites as in Hyidiothrips species. Abdominal terga III to VII each with one pair of well developed wing-retaining setae in macropterae; abdominal segment VIII with spiracle-bearing laterotergites separated from tergum in female. Tube tapering, shorter than head.

Remarks. This genus belongs to the hyidiothripine lineage, and is closely related to the genera Hyidiothrips Hood and Machadonia Bournier. It is easily distinguished from Hyidiothrips by the proportionately longer head, the expanded postocular setae, and the absence of the fore femoral median spine. From Machadonia, it is barely distinguished by the condition of the third and fourth antennal segments. These segments are well separated in Preeriella, although they are completely fused in Machadonia. However, the condition of these antennal segments in one Machadonia species, $M$. secticornis Bournier, 1965, and two new species described below, $P$. bournieri and $P$. malaya, is somewhat intermediate. They have the third and fourth segments closely joined, and scarcely separated by a complete suture between them. Moreover, a female and a male collected together with the type series of $P$. bournieri, and which are probably conspecific with it, have the third and fourth antennal segments well separated from each other (Figs 14, 15). Furthermore, P. malaya has the third and fourth antennal segments more or less fused with only an indistinct suture between them. Because of the presence of a morphocline from 'well separated' to 'completely fused' in the condition of the third and fourth antennal segments, the genus Machadonia is here treated as a junior synonym of Preeriella. Consequentially, the following five species are transferred to the genus Preeriella: $P$. brevicornis (Bournier, 1965), comb. n., P. crassisetis (Bournier, 1965), comb. n., P. discors Hood, 1957, comb. rev., P. pitkini (Hartwig, 1978a), comb. n., P. secticornis (Bournier, 1965), comb. n.

Particularly interesting are the intermediate abdominal terga of the 
hyidiothripine species, because they are distinctly narrow with the lateral sutures of the terga visible in dorsal view. This condition is also reported in some species of the genus Adraneothrips by Mound and Marullo (1996). However, the relationship between the hyidiothripine lineage and Adraneothrips is still uncertain.

\section{Key to Asian species of Preeriella}

1. Antennal segments III and IV well separated from each other (cf. Figs 27,29 ) $\cdots 2$

-. Antennal segments III and IV closely joined, but not completely fused, with a suture between them (cf. Figs 28, 30) …...............................................4

2. Abdominal tergum II without any sensorium-like organs; postocular cheek setae short, $10 \mu \mathrm{m}$ or shorter; males showing allometry, large males with enlarged hind legs bearing tibial subapical inner tubercle and tarsal tooth or hamulus

P. armigera sp. nov.

-. Abdominal tergum II with pair of circular sensorium-like organs (Fig. 17) situated near anterior margin at middle; postocular cheek setae well developed, longer than $15 \mu \mathrm{m}$

3. Body usually longer than $1 \mathrm{~mm}$ in female; body brownish, fore coxa and femur tinged with brown; prothoracic anteroangular setae longer than $60 \mu \mathrm{m} . \cdots . . . . . . .$.

..P. parvula Okajima

-. Body usually shorter than $1 \mathrm{~mm}$ in female; body yellowish, all legs largely yellow; prothoracic anteroangular setae shorter than $55 \mu \mathrm{m} \cdots \cdots \cdots . .$. . formosana sp. nov.

4. Head less than 2.0 times as long as wide, dorsal surface sculptured with reticles; prothoracic anteromarginal setae reduced, short and pointed; abdominal tergum II wider than long ….................................................. b. bournieri sp. nov.

-. Head more than 2.5 times as long as wide, dorsal surface almost smooth; prothoracic anteromarginal setae well developed; abdominal tergum Il a little longer than wide P. malaya sp. nov.

\section{Preeriella armigera sp. nov.}

(Figs 1-12, 20, 27)

Female (macroptera). Body length: $1.0-1.1 \mathrm{~mm}$. Colour yellowish; head and metathorax somewhat brownish, distinctly darker than abdomen, prothorax pale brownish yellow, slightly darker than abdomen and slightly paler than head, mesothorax and abdomen yellow to pale brownish yellow; all legs yellowish, but fore coxae more or less brownish; antennae somewhat brownish, almost concolourous with head or a little paler, but segments II and III yellowish; fore wings shaded with brown basally; major body setae almost hyaline.

Head (Fig. 1) about 1.7 times as long as broad, 1.71 times in holotype, broadest across eyes, dorsal surface almost smooth, faintly sculptured near base; postocular setae very weakly expanded or narrowly blunt at apex, at least not distinctly expanded, $22-23 \mu \mathrm{m}$ apart from eyes and $32.5 \mu \mathrm{m}$ apart from each other in holotype; cheeks almost straight or slightly concave, narrowed towards base, postocular cheek setae rather small, about $10 \mu \mathrm{m}$ long in holotype. Eyes and ocelli well developed. Antennae (Fig. 27) typical of genus, about 1.5 times as long as head. 
Pronotum 0.68 times as long as head in holotype, smooth; posteroangular setae expanded at apex, other prominent setae narrowly blunt or very slightly expanded at apex. Metanotum irregularly reticulated anteromedially, weakly sculptured with longitudinal anastomosing striae posteriorly at the middle. Fore wing with $37-38$ fringe hairs in holotype.

Abdominal tergum I (Fig. 3) typical of genus, median sclerite long and slender, posterior sclerite divided into two plates. B1 setae on abdominal tergum IX expanded at apex, longer than $\mathrm{B} 2$ but shorter than tube. Tube a little longer than half length of head, 0.54 times as long as head and 1.9 times as long as broad in holotype. Anal setae much longer than tube.

Measurements in $\mu m$ (holotype female). Total distended body length 1050 . Head length 100 , from anterior margin of eyes 87 , width across eyes 62 , across cheeks 60 , across cheeks just before basal collar 52; eye length 32-33, width 20-22. Prothorax median length 72 , width 102 ; fore wing length 415 . Pelta median sclerite length 22 , posterior sclerites width 63 . Tube length 57 , basal width 30 , apical width 17.5 . Antennal segments I to VIII length (width) as follows: $20(17) ; 26(20) ; 14(16) ; 23$ (23); 22 (19); 25 (14); 16 (8); 20 (5). Length of setae: postoculars 42-43; prothoracic anteroangulars 53-56, anteromarginals $20-21$, midlaterals $7-8$, posteroangulars $32-33$, epimerals 36 ; metathoracic medians less than 10 ; subbasal wings B1 28-29, B2 25, B3 ?-28; posteromarginals on tergum IX B1 42-44, B2 33-35; anals 75-85.

Female (microptera). Body length: About $1.0 \mathrm{~mm}$. Very similar in colour to macropterous female. Eyes (Figs. 4 and 5) smaller; ocelli absent. Metanotum transverse and smooth. Wing-retaining setae on abdominal terga reduced. Tube (Fig. 20) $0.55-0.59$ times as long as head.

Measurements in $\mu m$ (a paratype female). Total distended body length 980 . Head length 100 , from anterior margin of eyes 83 , width across eyes 52 , across cheeks 54 , across cheeks just before basal collar 52; eye length 20. Prothorax median length 71 , width 93; fore wing length 35 . Pelta median sclerite length 30 , posterior sclerites width 65 . Tube length 58 , basal width 32 , apical width 17.5 . Antennal segments I to VIII length (width) as follows: 20 (18); 26 (20); 15 (16); 24 (25); 23 (20); 26 (14.5); 17 (8); 20 (5). Length of setae: postoculars 38-42; prothoracic anteroangulars 47-49, anteromarginals 17-19, midlaterals 7-8, posteroangulars 33-34, epimerals 40; metathoracic medians 8-10; subbasal wings 22-28; posteromarginals on tergum IX $\mathrm{B} 1$ 40-42, B2 34-37; anals about 80.

Male (microptera) (Fig. 12). Body length: $0.8-1.0 \mathrm{~mm}$. Allometry evident. Head paler than in female, brownish yellow, almost concolourous with prothorax, slightly darkened anteriorly. Head (Fig. 6) structure almost as in micropterous female, but postocular cheek setae somewhat longer. Hind legs (Figs 7-9) extremely stout in large male: coxa enlarged, with stout tubercle at middle of inner margin; femur enlarged; tibia with subapical tubercle on inner margin; tarsus with stout tooth or hamulus. Abdomen stout, well sclerotized, especially in large male; lateral setae on abdominal terga long and stout; B1 and B2 setae on tergum IX also elongate, B2 almost as long as $\mathrm{Bl}$ or longer. Tube 0.5-0.6 times as long as head.

Measurements in $\mu \mathrm{m}$ (small/large paratype males). Total distended body length $870 / 1000$. Head length $97 / 108$, from anterior margin of eyes $77 / 87$, width across eyes $48 / 50$, across checks $50 / 52$, across cheeks just before basal collar $52 / 54$; eye length 20/22. Prothorax median length $75 / 90$, width $92 / 103$; fore wing length $30 /$ 42. Pelta median sclerite length $30 / 37$, posterior sclerites width $65 / 73$. Tube length 


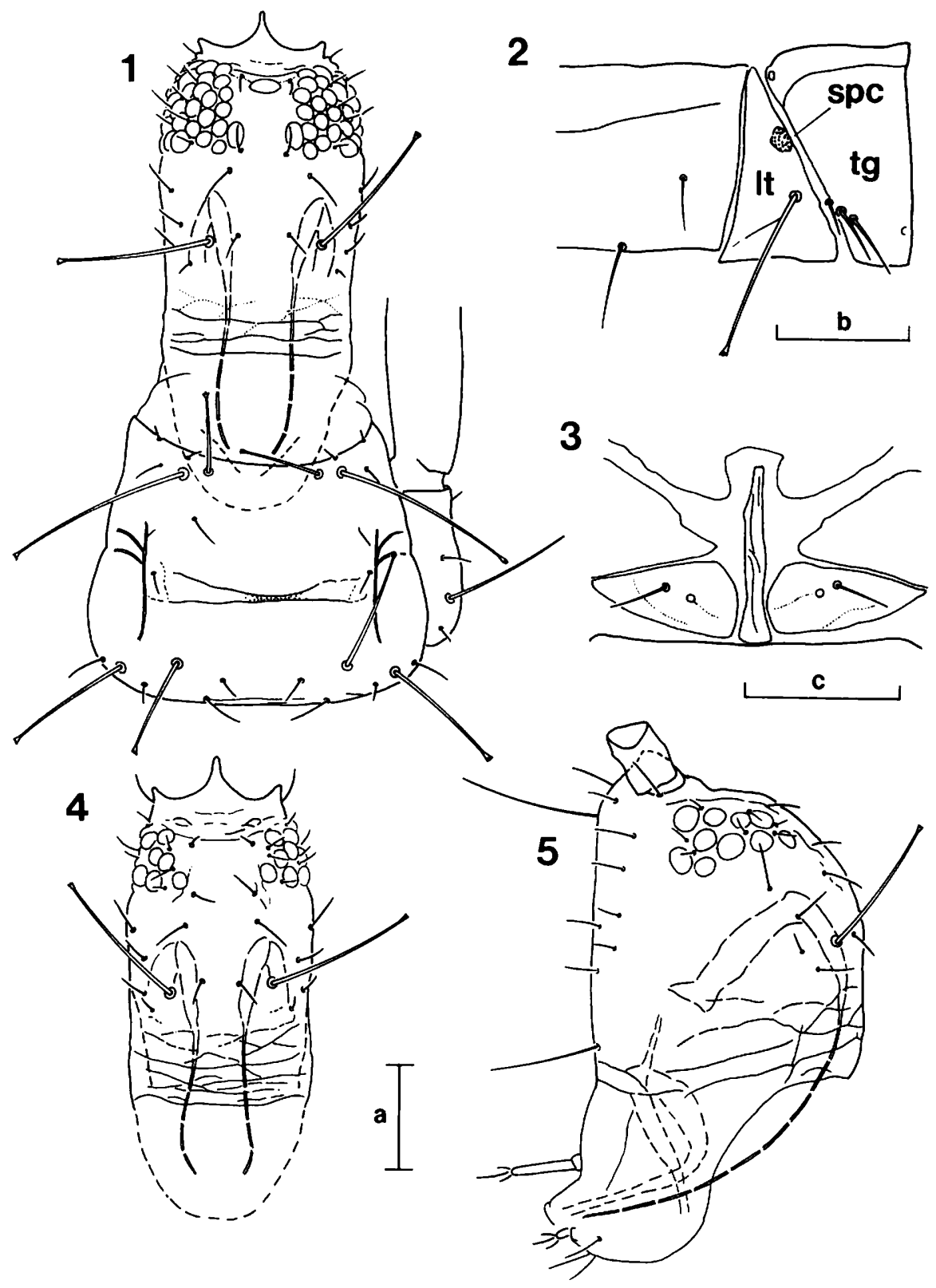

Figs 1-5. Preeriella armigera sp. nov. 1, head and pronotum, dorsal view, holotype female (mac.); 2, part of abdominal segment VIII, lateral view, paratype female (mac.), lt - laterotergite, spc spiracle, $\mathrm{tg}$ - tergum; 3 , abdominal tergum I, dorsal view, holoty pe female (mac.); 4, head, dorsal view, paratype female (mic.); 5 , head, lateral view, paratype female (mic.). Scales: $30 \mu \mathrm{m}$, a for 1, 4-5; b for 2 ; c for 3 . 
$48 / 65$, basal width $28 / 33$, apical width $17 / 20$. Antennal segments I to VIII length (width) as follows: $21 / 20(17.5 / 18) ; 25 / 27(19 / 20) ; 13 / 16(16 / 17) ; 22 / 25(22.5 / 24)$; $22.5 / 26(18 / 20) ; 23 / 25(15 / 15) ; 15 / 17(8 / 9.5) ; 19 / 22(5 / 6)$. Length of setae: postoculars 35-37/about 40; prothoracic anteroangulars 60-62/65-70, anteromarginals $20-22 / 27-30$, midlaterals $6-8 /$ about 10 , posteroangulars $32-33 / 42-46$, epimerals 45-47/60; metathoracic medians 6/about 10 ; subbasal wings $22-26 / 33-35$; posteromarginals on tergum IX B1 32-35/64-65, B2 53-55/73-75; anals 80-84/105.

Holoty pe. Female (mac.), Japan, Honshu, Nagano-ken, Ueda-shi, Sanada-machi, in leaf-litter, 29-xi-1995, T. Tsutsumi.

Paratypes. Japan: 23 females (mac.), 87 females and 41 males (mic.), collected with holotype.

Non-paratypic material. Taiwan: Chiai-hsien, nr. Kuantzulin, in leaf-litter, 1 female (mac.), 1 female and 10 males (mic.), 31-iii-1993, HU, 54 female and 5 males (mac.), 1 female and 58 males (mic.), 23-viii-1993, HU, TN and SO; 64 females and 3 males (mac.), 1 female and 32 males (mic.), Taitung-hsien, Chihpen, in leaf-litter, 10-ix-1993, HU; 3 females (mac.), 1 female and 6 males (mic.), Kaohsiung-hsien, Liukuei, in leaf-litter, 5-ix-1993, HU.

Distribution. Japan - Honshu (Nagano); ? Taiwan.

Etymology. The specific epithet is derived from the armed hind legs of male.

Remarks. An extensive series of females and males collected from Taiwan and housed in the collection of the Tokyo University of Agriculture is listed above among the non-paratypic material. They are very similar to $P$. armigera in appearance except for some small differences and are presumed to be conspecific with it. However, the locality of this population is far from the type locality, and the populations look well isolated. Although the type locality is located in the mountainous area of Central Honshu in a cool temperate region which is covered with deep snow in winter, the Taiwanese population occurs in a subtropical lowland region. The insects are probably moved easily by winds.

\section{Preeriella bournieri sp. nov.}

(Figs 13-16, 22, 28)

Female (macroptera). Distended body length: About $0.9 \mathrm{~mm}$. Bicoloured pale brown and yellow; head and metanotum pale brown, mesonotum shaded with brown posteriorly, the rest of body, including tube and legs, largely yellow; antennae gradually darkened distally, yellow to pale brown, segment I distinctly paler than head; fore wings shaded with brown in basal fifth; major body setae almost hyaline.

Head (Fig. 13) 1.6-1.7 times as long as wide, 1.64 times in holotype, broadest across cheeks just behind eyes, dorsal surface weakly sculptured with polygonal reticulation, reticles on ocellar region and base rather distinct; postocular setae weakly expanded at apex, 19-20 $\mu \mathrm{m}$ apart from eyes and $30 \mu \mathrm{m}$ apart from each other in holotype; cheeks very weakly concave, distinctly narrowed to base, postocular cheek setae reduced. Eyes and ocelli typical of genus, ommatidia large and few; posterior ocelli almost as large as neighboring ommatidium. Antennae (Fig. 28) eight-segmented, but segments III and IV closely joined, with complete suture between them; 1.67 times as long as head in holotype.

Pronotum (Fig. 13) 0.72 times as long as head in holotype, smooth, median 


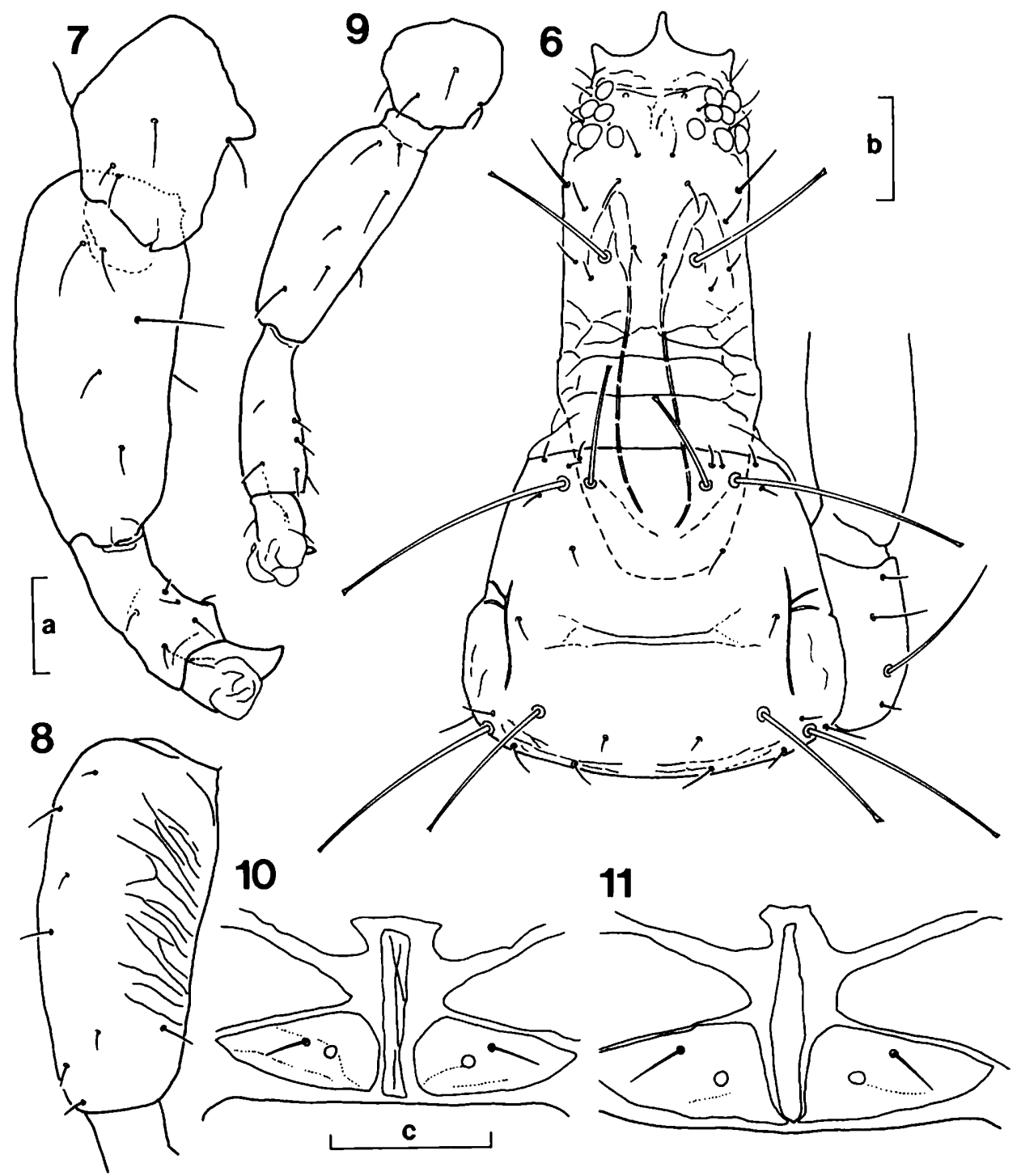

Figs 6-11. Preeriella armigera sp. nov., paratypes. 6, head and pronotum, dorsal view, male (mic.); 7, hind leg, ventral view, large male (mic.); 8, hind femur, dorsal view, large male (mic.); 9 , hind leg, ventral view, small male (mic.); 10, abdominal tergum I, dorsal view, female (mic.); 11 , abdominal tergum I, dorsal view, male (mic.). Scales: $30 \mu \mathrm{m}$, a for 7-9; b for 6; c for 10-11.

transverse groove distinct; anteroangular, epimeral, and posteroangular setae expanded at apex, anteroangulars the longest, posteroangulars much shorter than epimerals, anteromarginals reduced to short and pointed setae, situated before the level of anteroangulars. Notopleural suture rather clearly developed, proepisternum distinct from pronotum. Metanotum distinctly reticulated anteromedially, reticles 


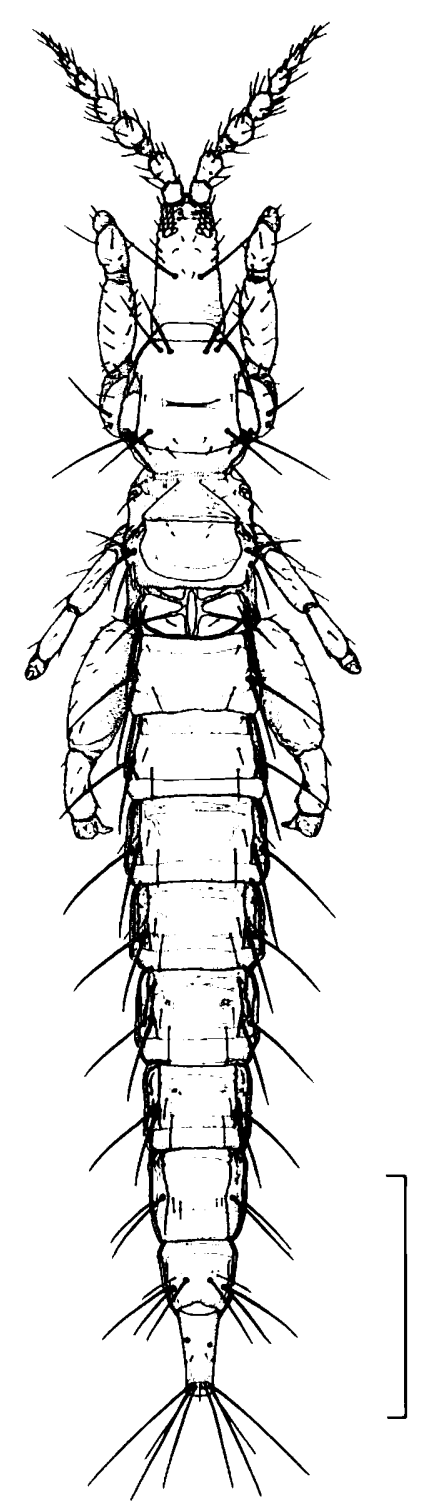

Fig. 12. Preeriella armigera sp. nov., dorsal view, paratype large male (mic.). Scale: $200 \mu \mathrm{m}$.

with internal fine wrinkles; also sculptured with some reticles and wrinkles posteriorly at the middle, but more weakly. Fore wing with $30-34$ fringe hairs in holotype.

Abdominal tergum I (Fig. 16) typical of genus, median sclerite long and slender, posterior sclerite divided into two plates, anterior sclerite weak and eroded. Wingretaining setae on abdominal terga short and rather straight. B1 and B2 setae on abdominal tergum IX subequal in length, much shorter than tube, expanded at apex. 
Tube (Fig. 22) 0.57 times as long as head and 1.72 times as long as wide in holotype. Terminal setae almost as long as tube or a little longer.

Measurements in $\mu m$ (holotype female). Total distended body length 940 . Head length 97 , from anterior margin of eyes 81 , width across eyes 58 , across cheeks just behind eyes 59 , across cheeks before basal collar 51 ; eye length 25 , width 22-23. Prothorax median length 70, width 95; fore wing length 345 . Pelta median sclerite length 31 , posterior sclerites width 66 . Tube length 55 , basal width 32 , apical width 16. Antennal segments I to VIII length (width) as follows: 18 (17.5); 27.5 (21); 14 (18); 23 (23); 22 (17); 26 (12.5); 15.5 (8); 20 (5). Length of setae: postoculars 22-23; prothoracic anteroangulars 28-30, anteromarginals 5-6, posteroangulars 12-13, epimerals 23-25; metanotal medians reduced; posteromarginals on tergum IX B1 33-34, B2 30-33; terminals 55-60.

Male. Unknown.

Holotype. Female (mac.), Thailand, near Chiang Rai, in leaf-litter, 5-ix-1992, TN and SO.

Paratypes. Thailand: 76 females (mac.), collected together with holotype.

Non-paratypic material. Thailand: 1 female and 1 male (mac.), collected together with holotype.

Distribution. Thailand.

Etymology. The specific name is dedicated in honour of Prof. Dr. Alexandre Bournier, one of the most well known Thysanoptera specialists.

Remarks. Preeriella bournieri is similar to $P$. secticornis in having similar segmentation of the third and fourth antennal segments (Fig. 28). However, it is easily distinguished by the reduction of the prothoracic anteromarginal setae and the long and slender shape of the median sclerite of the first abdominal tergum.

Two macropterous individuals, one female and one male, listed above as non-paratypic material, were collected together with the type series of this species and they are presumed to be conspecific with it. However, they have the third and fourth antennal segments well separated (Figs 14,15), whereas females in the type series of $P$. bournieri all have these segments closely fused (Fig. 28).

\section{Preeriella formosana sp. nov.}

(Figs 17-19, 21, 29)

Female (macroptera). Distended body length: $0.9-1.0 \mathrm{~mm}$. Colour yellowish, partly slightly shaded with brown; head and pronotum brownish yellow to yellow, ocellar region somewhat darker, mesonotum yellow, metanotum brownish yellow, abdomen and tube yellowish; all legs yellowish, often very slightly shaded with grey; antennae pale greyish brown, but segments I to III somewhat paler; fore wings slightly shaded with brown basally; prominent body setae almost hyaline.

Head (Fig. 18) about 1.8 times as long as wide, 1.80 times in holotype, widest across cheeks just behind eyes or across eyes; dorsal surface almost smooth, weakly sculptured in ocellar region and near base; postocular setae long and slender, expanded at apex, 20-21 $\mu \mathrm{m}$ apart from eyes and $33 \mu \mathrm{m}$ apart from each other in holotype. Eyes and ocelli well developed; posterior ocelli much larger than neighbouring ommatidia. Antennae (Fig. 29) eight-segmented, about 1.5 times as long as head, 1.48 times in holotype; segments III and IV well separated. 

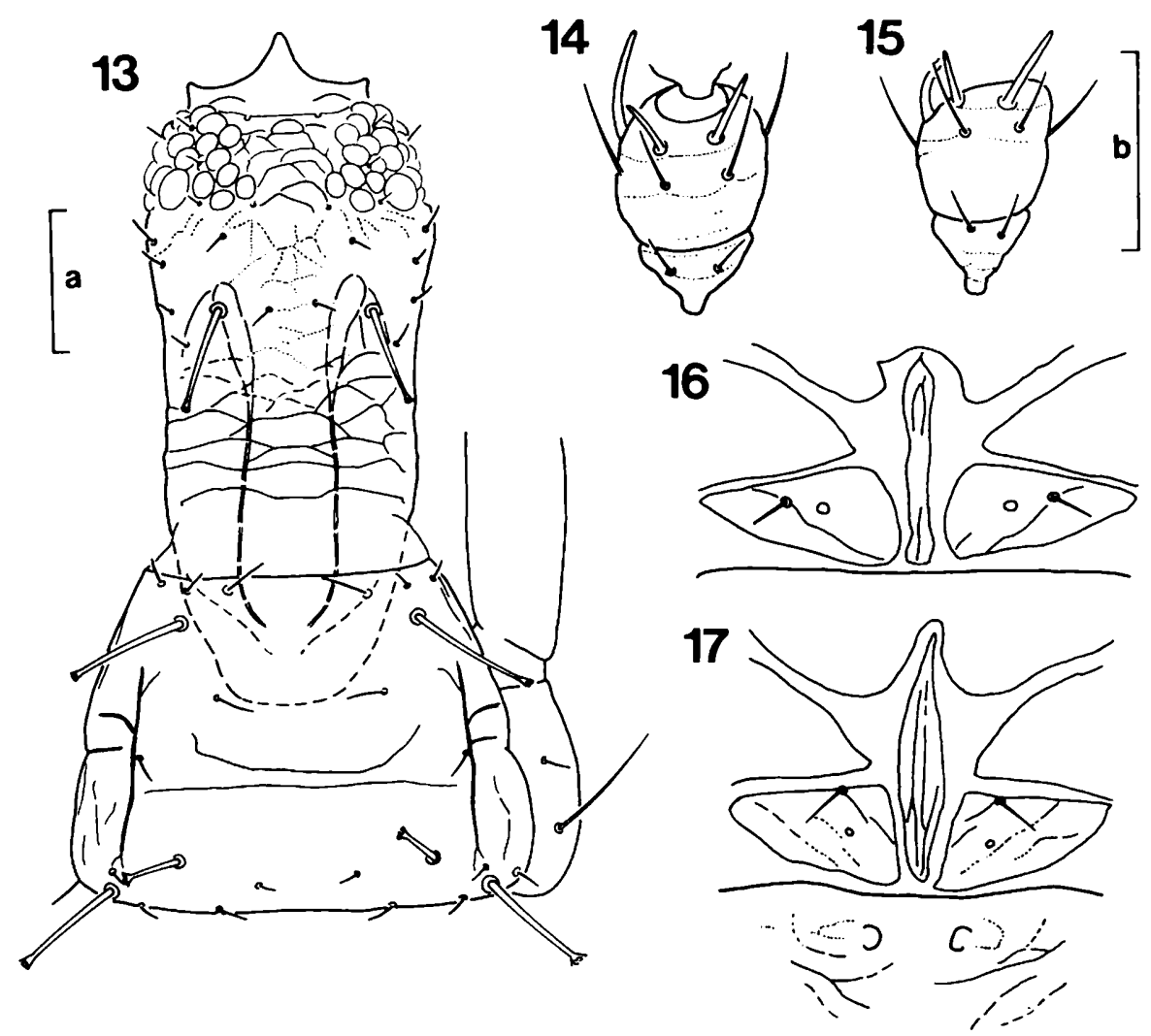

Figs 13-16. Preeriella bournieri sp. nov. 13, head and pronotum, dorsal view, holotype female (mac.); 14, antennal segments III and IV, dorsal view, non-paratypic female (mac.); 15, antennal segments III and IV, dorsal view, non-paratypic male (mac.); 16, abdominal tergum I, dorsal view, holotype female (mac.). Fig. 17. Preeriella formosana sp. nov., abdominal tergum I and anterior portion of tergum II, dorsal view, holotype female (mac.). Scales: $30 \mu \mathrm{m}$, a for 13; b for $14-17$.

Pronotum (Fig. 18) 0.62 times as long as head in holotype, smooth, median transverse groove rather weak; prominent setae of prothorax well developed, expanded at apex but slender, anteroangulars the longest, anteromarginals a little more than half as long as anteroangulars. Notopleural suture rather weak, proepisternum not distinct from pronotum. Metanotum reticulated anteromedially, reticles with internal wrinkles; longitudinally finely striated posteromedially. Fore wings with 36-37 fringe hairs in holotype.

Abdominal tergum I (Fig. 17) typical of genus, median sclerite long and slender, narrowed anteriorly, posterior sclerite divided into two plates. Abdominal tergum II with pair of small, circular, sensorium-like organs situated near anterior margin at middle (Fig. 17); B1 on abdominal tergum IX weakly expanded or blunt at apex, at least not pointed, almost as long as tube or a little longer, B2 setae pointed at apex, 


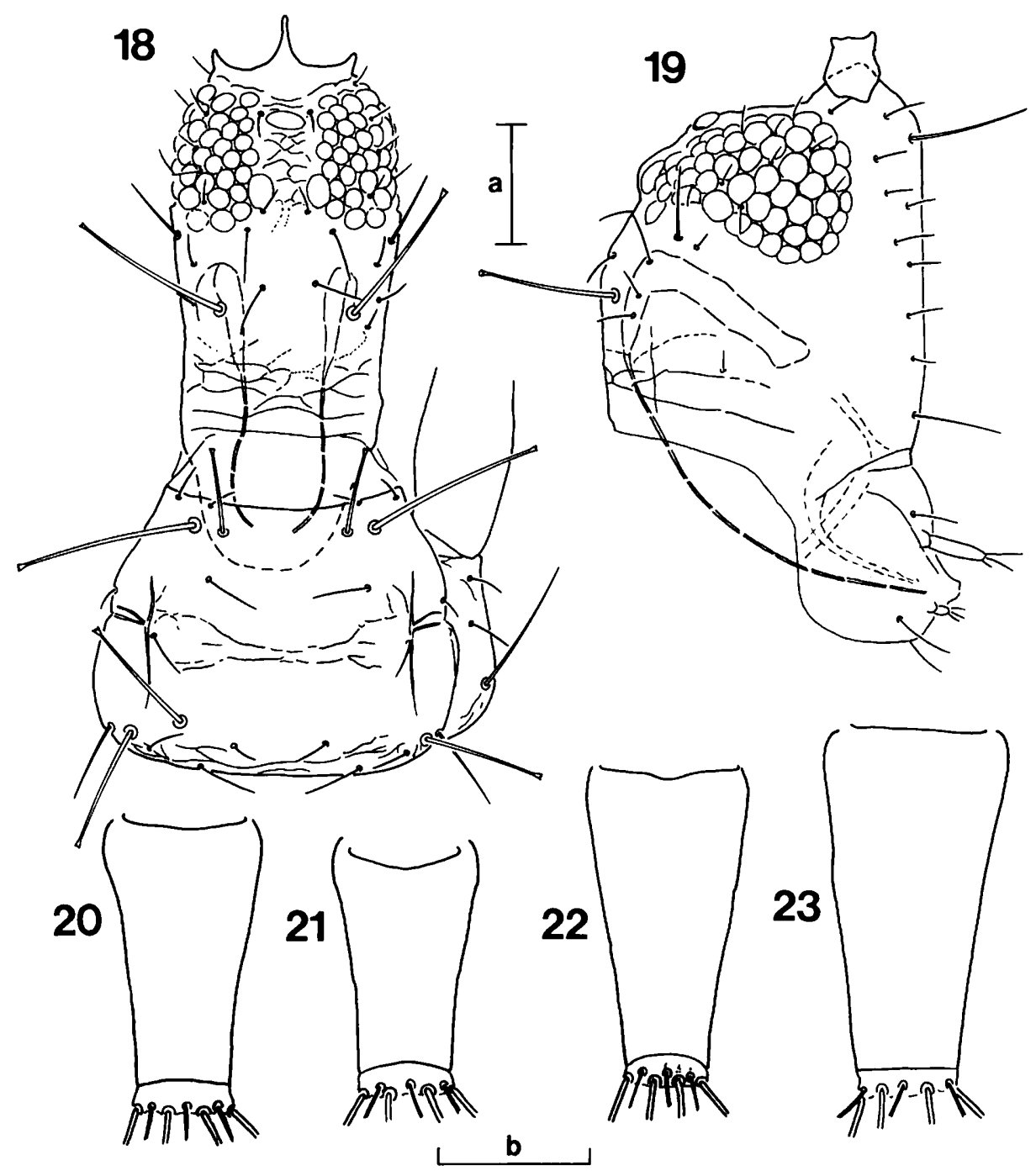

Figs 18, 19. Preeriella formosana sp. nov. 18, head and pronotum, dorsal view, holotype female (mac.); 19, head, lateral view, paratype female (mac.). Figs 20-23. Tubes of Preeriella species, dorsal view, holotype females (mac.). 20, P. armigera sp. nov.; $21, P$. formosana sp. nov.; $22, P$. bournieri sp. nov.; 23, P. malaya sp. nov. Scales: $30 \mu \mathrm{m}$, a for 18-19; b for 20-23.

almost as long as B1. Tube (Fig. 21) short, about 0.4 times as long as head, 0.41 times in holotype, about 1.6 times as long as basal width in holotype. Terminal setae much longer than tube.

Measurements in $\mu m$ (holotype female). Total distended body length 970 . Head length 110 , from anterior margin of eyes 91 , width across eyes 60 , across cheeks just behind eyes 61 , across cheeks before basal collar 52; eye length 38-40, width 23-24. 
Prothorax median length 68 , width 96; fore wing length 410 . Pelta median sclerite length 40 , posterior sclerites width 60 . Tube length 45 , basal width 28 , apical width 17.5. Antennal segments I to VIII length (width) as follows: 20 (18); 26 (20); 13 (17.5); 23 (24); 27 (20); 24 (14); 15 (8); 17 (5). Length of setae: postoculars 42-45; prothoracic anteroangulars $50-52$, anteromarginals $23-25$, posteroangulars $32-33$, epimerals 35; metanotal medians less than 10; posteromarginals on tergum IX B1 43-46, B2 45-47; terminals 70-75.

Male. Unknown.

Holotype. Female (mac.), Taiwan, Chiai-hsien, near Kuantzulin, in leaf-litter, 23-viii-1993, HU, TN and SO.

Paratypes (196 females in total). Taiwan: 70 females (mac.), collected together with holotype; 3 females, data as for holotype, but 31-iii-1993, HU; Nantou-hsien, Nanshanchi, in leaf-litter, 6 females (mac.), 3-iv-1993, 109 females (mac.), 29-viii1993, HU; 8 females (mac.), Kaohsiung-hsien, Liukuei, in leaf-litter, 5-ix-1993, HU.

Distribution. Taiwan.

Etymology. The specific epithet refers to the type locality, Formosa (= Taiwan).

Remarks. Preeriella formosana is undoubtedly closely related to $P$. parvula Okajima, 1978, described from West Malaysia. These two species share a pair of campaniform, sensorium-like organs on the second abdominal tergum, eightsegmented antennae, well developed postocular cheek setae, a divided posterior sclerite on the first abdominal tergum, and a relatively short tube. Although the present species is known only from females, $P$. parvula is known from both sexes. There is a possibility that these two nominal species are merely local populations of the same species, but they can be distinguished by characters given in the key above.

Preeriella malaya sp. nov.

(Figs 23-26, 30)

Female (macroptera). Distended body length: $1.3-1.4 \mathrm{~mm}$. Very slender and feeble species. Colour generally yellow; antennae slightly shaded with grey distally; fore wings shaded with pale brown basally; prominent body setae almost hyaline.

Head (Figs 24 and 25) elongate, much more than twice as long as wide, about 2.6 times as long as wide in holotype, widest across eyes, dorsal surface almost smooth, preocular projection well developed; postocular setae stout, club-like, not expanded but thick at apex, rather close together, $38-40 \mu \mathrm{m}$ apart from eyes, $19 \mu \mathrm{m}$ apart from each other in holotype; cheeks slightly concave or almost straight, postocular cheek setae well developed, a little longer than half of length of postocular setae, about 3 $0 \mu \mathrm{m}$ in holotype. Eyes and ocelli well developed; posterior ocelli close together, $5 \mu \mathrm{m}$ apart from each other, almost as large as neighboring ommatidia. Antennae (Fig. 30) morphologically eight-segmented, but segments III and IV fused and appearing as one segment, with indistinct suture between them; about 1.2 times as long as head. Maxillary stylets rather close together at middle of head, $5 \mu \mathrm{m}$ apart from each other in holotype.

Pronotum (Fig. 24) about 0.6 times as long as head, very weakly sculptured with transverse fine striae, median transverse groove indistinct; prominent setae clubshaped like postocular cephalic setae, anteroangulars the longest, anteromarginals situated just before level of anteroangulars. Notopleural suture rather weak, 

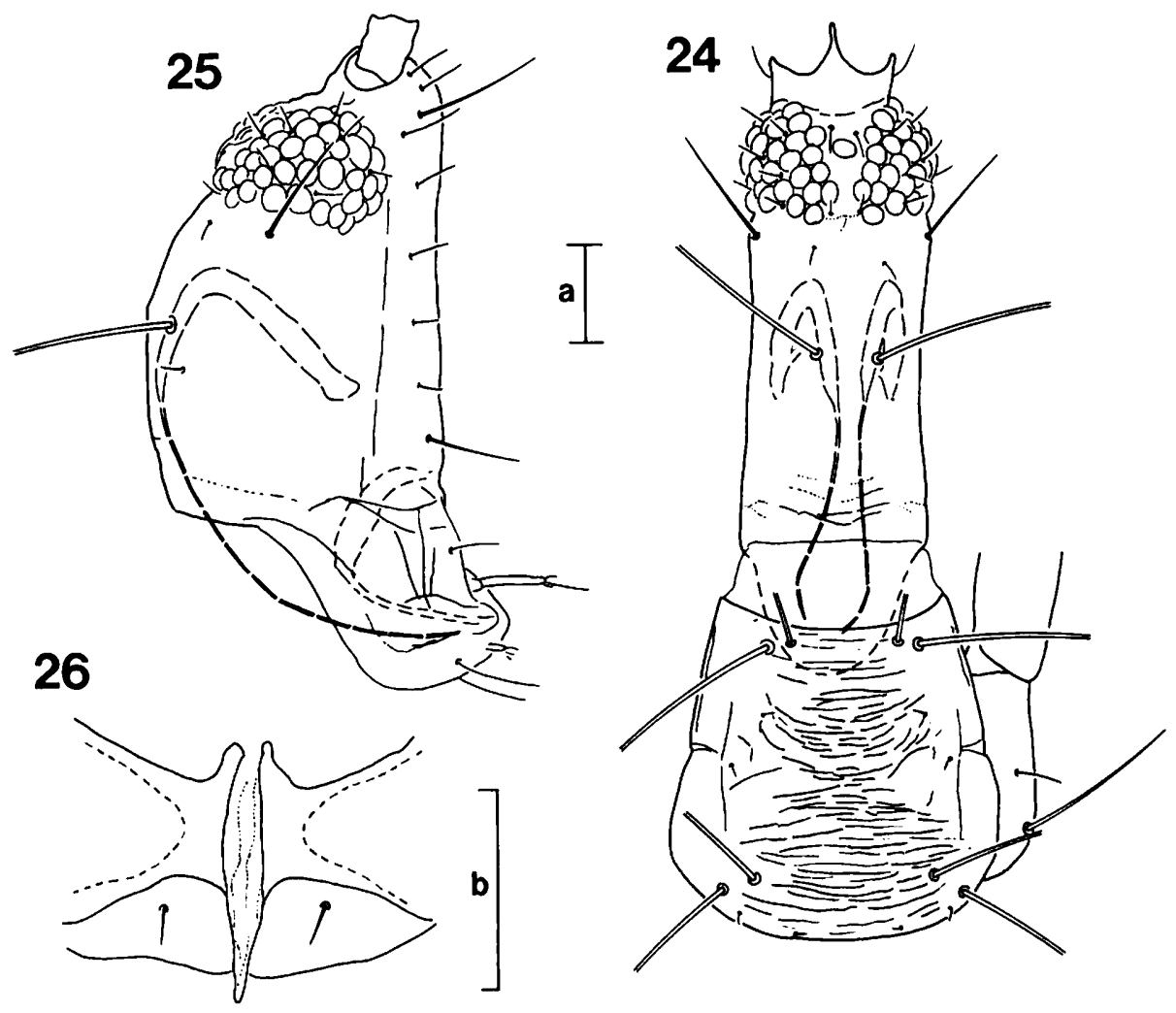

Figs 24-26. Preeriella malaya sp. nov., females (mac.). 24, head and pronotum, dorsal view, holoty pe; 25 , head, lateral view, paratype; 26 , abdominal tergum I, dorsal view, holoty pe. Scales: $30 \mu \mathrm{m}$, a for 24-25; b for 26.

proepisternum not distinct from pronotum. Metanotum weak, very weakly sculptured with fine longitudinal striae at middle. Fore wing with 34-35 fringe hairs; three subbasal setae club-shaped, but very weakly expanded.

Abdominal tergum I (Fig. 26) typical of genus but fecble, median sclerite long and slender and fused to anterior sclerite, posterior sclerite divided into two plates. Abdomen long and slender, tergum Il a little longer than wide; wing-retaining setae on terga III to V stout and rather straight, on tergum VI sigmoid, on tergum VII short; B1 setae on tergum IX weakly expanded at apex, a little shorter than tube, B2 on tergum IX elongate and slender, sharply pointed, much longer than tube. Tube (Fig. 23) about 0.4 times as long as head, 0.41 times in holotype, 1.86 times as long as basal width in holotype. Terminal setae weak, longer than tube.

Measurements in $\mu m$ (holotype female). Total distended body length 1340 . Head length 159, from anterior margin of eyes 133 , width across eyes 61 , across cheeks just behind eyes 60 , across cheeks before basal collar 57; eye length 35-37, width 24-28. Prothorax median length 94, width 102; fore wing length 490 . Pelta median sclerite length 42 , posterior sclerites width 60 . Tube length 65 , basal width 35 , apical width 


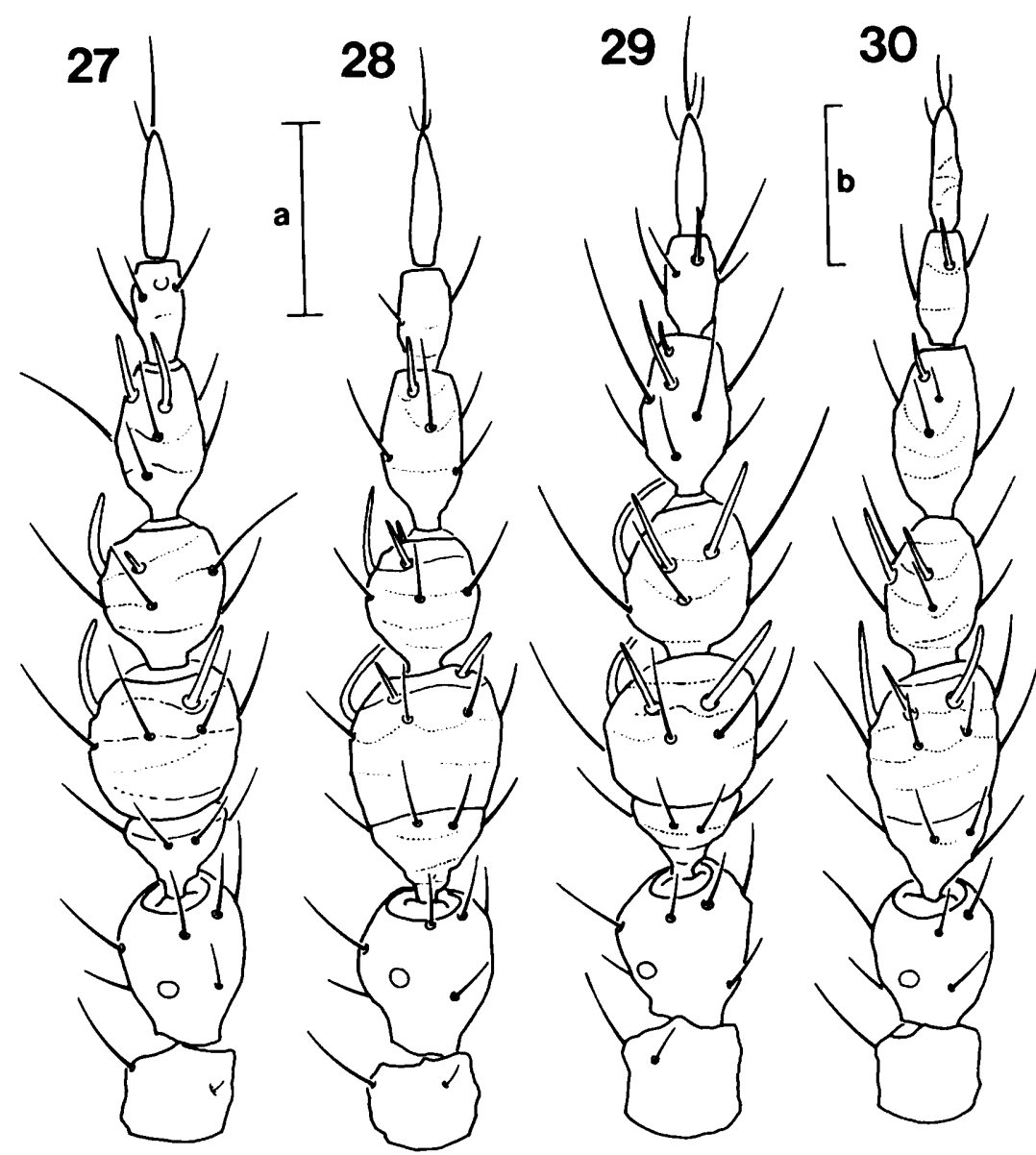

Figs 27-30. Left antennae of Preeriella species, dorsal view, holotype females (mac.). 27, $P$. armigera sp. nov.; $28, P$. bourmieri sp. nov.; $29, P$. formosana sp. nov.: $30, P$. malaya sp. nov. Scales: $30 \mu \mathrm{m}$, a for 27-29; b for 30 .

20. Antennal segments length (width) as follows: I 22 (20); II 27 (22); III+IV 45 (25); V 27 (17.5); VI 32 (15); VII 20 (9.5); VIII 23 (6). Length of setae: postoculars 55-56; prothoracic anteroangulars $52-55$, anteromarginals about 20 , posteroangulars 35-37, epimerals about 40; metanotal medians reduced; subbasal wings 30-40; posteromarginals on tergum IX B1 62-64, B2 100-103; terminals 82-84.

Male. Unknown.

Holotype. Female (mac.), West Malaysia, about $20 \mathrm{~km} \mathrm{~N}$ of Kuala Lumpur, near Templer Park, on bamboo, 12-ix-1990, TN and SO.

Paratypes. West Malaysia: 2 females, collected together with holotype.

Distribution. West Malaysia.

Etymology. The specific epithet is derived from the type locality, West Malaysia. Remarks. Preeriella malaya has the third and fourth antennal segments closely 
fused with an indistinct suture between them, and an elongate head which is more than 2.5 times as long as the width across the eyes. By the combination of these features, it is readily distinguished from its congeners.

\section{Acknowledgements}

The present author wishes to express his cordial thanks to Prof. L. A. Mound, the Natural History Museum, London, for his expert suggestions after reading through the manuscript. Thanks are also due to Dr. T. Tsutsumi, Fukushima University, Dr. T. Nonaka, Tokyo, and Miss H. Urushihara, Omogo Mountain Museum, Ehime, for their kindness in offering specimens.

\section{References}

Bhatti, J. S. 1992. The order Tubulifera (Insecta): Its characters and classification into families. Zoology (Journal of Pure and Applied Zoology) 3: 127-162.

Bournier, A. 1965. Thysanoptéres de 1'Angola. III. Publicaçoes Culturais da Companhia de Dimantes de Angola, Separata 72: 87-106.

Crespi, B. 1986a. Territorial and fighting in a colonial thrips, Hoplothrips pedicularius, and sexual dimorphism in Thysanoptera. Ecological Entomology 11: 119-130.

Crespi, B. 1986b. Size assesment and alternative fighting tactics in Elaphrothrips tuberculatus (Insecta: Thysanoptera). Animal Behaviour 34: 1324-1335.

Crespi, B. 1988. Risks and benefits of lethal male fighting in the colonial, polygynous thrips Hoplothrips karnyi (Insecta: Thysanoptera). Behavioral Ecology and Sociobiology 22: 293-301.

Hartwig, E. K. 1978a. Two new species of Hyidiothripini (Thysanoptera, Phlaeothripidae) from South Africa, with notes on two known species. Journal of the Entomological Society of Southern Africa 41: 149-158.

Hartwig, E. K. 1978b. A new species of Preeriella (Thysanoptera, Phlaeothripidae) from South Africa with comments on Hyidiothripini characters. Journal of the Entomological Society of Southern Africa 41: 259-264.

Hood, J. D. 1938. New Thysanoptera from Florida and North Carolina. Revista de Entomologia, Rio de Janeiro 8: 348-420.

Hood, J. D. 1939. New North American Thysanoptera, principally from Texas. Revista de Entomologia, Rio de Janeiro 10: 550-619.

Hood, J. D. 1957. New Brazilian Thysanoptera. Proceedings of the Biological Society of Washington 70: 129-180.

Mound, L. A. and Marullo, R. 1996. The thrips of Central and South America: An introduction. Memoirs on Entomology International 6: 1-488.

Mound, L. A. and Marullo, R. 1997. The Hyidiothrips genus-group from tropical leaf-litter (Thysanoptera Phlaeothripidae), with two new species of the Old-World genus Crinitothrips Okajima 1978. Tropical Zoology 10: 191-202.

Okajima, S. 1978. Notes on the Thysanoptera from Southeast Asia IV. A new genus and two new species of the tribe Hyidiothripini (Phlaeothripidae). Kontyû 46: 539-548.

Okajima, S. 1998. The genus Andrethrips (Thysanoptera: Phlaeothripidae), with description of a new species. Entomological Science 1: 71-76. 